\title{
The Materiality of Cylinder Seals
}

In the 1980ies Dr. Julia Asher-Greve conducted chemical and mineralogical material analysis on cylinder seals as a part of her SNFfunded project „Naturwissenschaftliche und typologische Untersuchungen an Rollsiegeln“. 1017 seals have been analysed using the non-destructive methods of EDS-XFA (energy dispersive X-ray fluorescence analysis) for chemical classification and XRF (X-ray diffraction) for mineralogical classification. This was one of the first large scale projects on Mesopotamian glyptic with its main focus on materiality rather than style, iconography or inscription as was usually the case when working on cylinder seals. Since then much work on the materiality of seals has been done, mostly by institutions such as the British Museum. This is because those institutions have access to large seal corpora and they either have the funds to pay for the costly analysis or possess the means to analyse the seals themselves.

As I 'inherited' the unfinished project of Dr. Asher-Greve including the analysis (which still need to be interpreted), I am painfully aware of the difficulties and problems to be encountered with such old analysis. In my 10-minute talk I will give an insight to the chances and limitations of scientific material analysis on archaeological artefacts. For especially small and precious objects like cylinder seals need to be treated with the uttermost care and under no circumstances should they take damage in the process of being analysed. 